\title{
Resolving and Assigning N-Linked Glycan Structural Isomers from Ovalbumin by IMS-MS
}

\author{
Manolo D. Plasencia, Dragan Isailovic, Samuel I. Merenbloom, \\ Yehia Mechref, and David E. Clemmer \\ Department of Chemistry, Indiana University, Bloomington, Indiana, USA
}

\begin{abstract}
Ion@nobility-mass@pectrometryథIMS-MS)@nd@nolecular@nodeling@echniques@lave@ieen@sed to@haracterize@valbumin@N-linked@lycans. Some@lycans@rom@his@lycoprotein@xist@s multiple@someric@orms.đhe@as-phase@eparation@nakes@tpossible@o@esolve@ome@somers before@MS@nalysis.@omparisons@f@xperimental@ross@ections@or@elected@lycan@somers with@values@hat@are@calculated@for@iterative@structures@generated@by@molecular@modeling techniques@llow@he@ssignment@f@harp@eatures@o@pecific@somers.@e@ocus@here@n@n

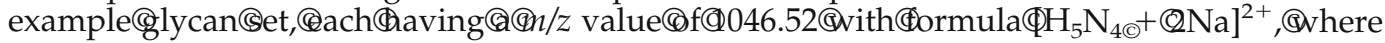
H@orresponds@o@(hexose,@nd@N@o@@V-acetylglucosamine.đThis@lycan@ppears@o@xist@s three@ifferent@someric@orms@hat@re@ssignable@based@n@omparisons@f@measured@nd calculated@ross@ections.@Ve@stimate@he@elative@atios@f(4he@bundances@f@he $₫$ hree@somers to@ben@ehe@ange@f@- 1.0:1.35:0.85@o@ 1.0:1.5:0.80.@n@otal,@MS-MS@nalysis@f@valbumin N-linked@glycans@provides@evidenceđfor@19@different@glycan@structures@corresponding@to high-mannose@nd@ybrid@ype@arbohydrates@ith@@otal@f@2@istinct@eatures@elated@o isomers@nd /or@onformers.@ (J@m@oc@Mass@pectrom@008,@9,(®706-1715)@@008@merican Society@ior@Mass@spectrometry
\end{abstract}

$\mathrm{G}$ lycosylation@s@mong@he@most@requently@bserved@post-translation@modifications@of@proteins\$1,(2]@nd@s@ssociated@ith@he@onformational@ stability,@ physicochemical@ properties@ (e.g., solubility,@esistance@o@nzymatic@egradation),@ellular transport,@r@ell-cell@interactions@3,@4].@nlike@ther modifications,@@ingle@lycosylation@ite@an@enerate substantial@heterogeneity.CFor@example,@ovalbumin,(C) 385@residue@glycoprotein, $\mathbb{A s} @$-glycosylated@nly@ $@$ single@ite, $₫$ he@ $\left(22^{\text {nd }}\right.$ asparagine@esidue. $₫$ et, $($ nore $₫$ han 30@pecies $₫$ having@ifferent@nass-to-charge $(\mathrm{m} / \mathrm{z}) @$ alues corresponding@o@high-mannose@and Chybrid@N-linked glycans@areCreported@to@be@associated@with@this@site [5-11].CThis@omplexity@arises@rom@the@template-free nature@f@lycosylation, $₫$ hus@rompting@he@ormation of@nany@tructures,@nany@)@hich@re@somers.

A@ubstantial(factor@hat@imits@ur@nderstanding@f the@ole@f@lycoproteins@n@iological@rocesses@s@hat few@xperimental@echniques@an@rovide@nformation about@theseđisomeric@structures, @especially@when@obtained@rom@iological@ources@t@inute@uantities@and often@s@nixtures).đraditionally,@etailed@haracterization@®lycans@n@(biological@ixture@elies@n@he@se of@@ide@ariety@f@nalytical@nethodologies,@ncluding condensed@hase@eparations $₫ 12, \Subset 3]$,@hemical@erivatization@[14], Cand@more@recently@mass@spectrometric (MS)@ndథandem $₫$ MS $\left.\left.₫ M^{n}\right) \oplus e c h n i q u e s థ 15-17\right]$.

Address reprint requests to Dr. D. E. Clemmer, Department of Chemistry, Indiana University, 800 E. Kirkwood Ave., Bloomington, IN 47405, USA. E-mail:@lemmer@indiana.edu
In@ecent@ears,@everal@roups@have@eveloped@on mobility-mass@spectrometry@(IMS-MS)@echniques@for the@nalysis@f@omplex@rotein@ind@eptide@nixtures [18-23].đIMS-MSCtechniquesđincorporate@a@gas-phase

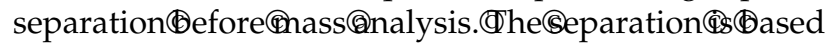
on@ifferences@n@on@nobilities@hrough@he@uffer@as, which@riginate@rom@ifferences@n@hape@nd@harge. These@eparations@ccur@n@nillisecond@imescales@nd information $₫$ hat $₫ s @ b t a i n e d @ a n @ o m p l e m e n t @ M S-b a s e d$ assignment@nethods.đHere,@ve@xplore@he@se@f@MS for@he@nalysis@f@lycans@vith@he@im@f@ising@he approach@to@ifferentiate@onformational@differences@f speciesChaving@imilar@antennary@substitutions@hat@are connected@t@ifferent@ositions@o@he@rimannosyl-chitobiose@ore.đn@this@ase, @he@assignment@of@isomers would@e@ifficult@ince@he@lycosidic@ragments@ypically@bserved@n@MS ${ }^{\text {n }}$ experiments@would@e@mbiguous.@However, @hese@tructures@an@have@ifferent@eometries $\odot$ in $\odot$ the $\odot$ gas $($ phase $\odot$ that $\odot$ are $\odot$ amenable $\odot$ to separation@sing@n@MS-MS@pproach.đThe@omplexities@nentioned@bove, $₫$ @ombination@rith $₫$ he@ack@f automated@equencing@ools, (have@imited@he@highthroughput analysis of complicated carbohydrate mixtures. Several research groups have demonstrated the benefits of incorporating ion mobility separations for determining structural differences in small oligosaccharides and simple mixtures [24-28].

The present work focuses on the analysis of N-linked glycans enzymatically released from ovalbumin using an IMS-TOF/MS approach. The permethylated digest
(C) 2008 American Society for Mass Spectrometry. Published by Elsevier Inc. $1044-0305 / 08 / \$ 32.00$

doi:10.1016/j.jasms.2008.07.020
Published online July 31, 2008 Received July 1, 2008 Revised July 24, 2008 Accepted July 25, 2008 
was electrosprayed directly into the instrument without the use of more complicated separation methods. In the analysis of ovalbumin, we find that a thorough examination of the glycan profile, including gas-phase structural information, could be performed by the incorporation of a dispersive ion mobility separation before mass analysis. The structural information obtained from mobility data were translated into differences in shapes of the molecules and precise cross sectional areas were measured. The cross sections were then used to assign isomers using data obtained from molecular modeling results. Since IMS-MS separations use a dispersive approach without mass selection, quantitative information about the system should be accessible through the relative intensities of different features (corresponding to different isomers) in the IMS distributions.

\section{Experimental}

\section{Isolation of $\mathrm{N}$-Linked Glycans from Ovalbumin}

Peptide N-Glycosidase F (PNGase F, >95\% purity) of Flavobacterium meningosepticum was purchased from Sigma Chemical Co. (St. Louis, MO). HPLC grade acetonitrile and water were purchased from EMD Chemicals ( $\geq 99.9 \%$ purity, Gibbstown, NJ). Ovalbumin Grade VI ( $>98 \%$ purity) and all other reagents were obtained from Sigma Chemical Co.

A microtube digestion and permethylation procedure was used to obtain the N-linked glycans from ovalbumin. The details of the procedure have been reported elsewhere [29-32]. Briefly, $5 \mathrm{mg}$ of ovalbumin was dissolved in $10 \mathrm{mM}$ sodium phosphate buffer $(\mathrm{pH}$ 7.5) followed by addition of PNGase F at a concentration of 50 milliunits of enzyme per $\mathrm{mg}$ of glycoprotein. The reaction mixture was incubated at $37^{\circ} \mathrm{C}$ for $18 \mathrm{~h}$. The N-linked glycans were purified using C18 Sep-Pak solid-phase extraction (SPE) cartridges (Waters Corp., Milford, MA) following conditioning and equilibrating steps with ethanol and water, respectively. Glycans present in the SPE flow-through were then passed over activated charcoal microcolumns (Harvard Apparatus, Holliston, MA) preconditioned with $1 \mathrm{~mL}$ of acetonitrile and $1 \mathrm{~mL}$ aqueous solution of $0.1 \%$ trifluoroacetic acid (TFA). The microcolumn was washed with $1 \mathrm{~mL}$ of $0.1 \%$ TFA and samples were eluted with a 1-mL aliquot of $50 \%$ aqueous acetonitrile with $0.1 \%$ TFA. The purified $\mathrm{N}$-glycans were evaporated to dryness using a vacuum CentriVap Concentrator (Labconco Corporation, Kansas City, MO) before solid-phase permethylation. Purified glycans were permethylated by using a recently developed spin-column permethylation procedure [32]. Briefly, an empty microcolumn (Harvard Apparatus, Holliston, MA) was packed with sodium hydroxide beads (80 mesh) and suspended in dimethyl sulfoxide (DMSO). The dried glycan sample was dissolved in 93 $\mu \mathrm{L}$ of DMSO (3\% vol/vol $\left.\mathrm{H}_{2} \mathrm{O}\right)$ followed by the addition of $33.6 \mu \mathrm{L}$ of iodomethane. The reaction mixture was passed through the spin column eight times; 300 $\mu \mathrm{L}$ of chloroform was added to the mixture and extracted four times with $300 \mu \mathrm{L}$ of $\mathrm{H}_{2} \mathrm{O}$. The chloroform layer containing the permethylated glycans was evaporated to dryness using a CentriVap concentrator.

A fraction of the dried sample was reconstituted in 50:50 acetonitrile:water $(0.2 \%$ formic acid, vol/vol; 2 $\mathrm{mM}$ sodium acetate) to a final concentration of 0.25 $\mathrm{mg} / \mathrm{mL}$ before IMS-MS analysis. The glycan solution is delivered to the electrospray emitter $(2 \mathrm{kV})$ at a flow rate of $250 \mathrm{~nL} \cdot \mathrm{min}^{-1}$ using a syringe pump (KD Scientific, Holliston, MA) fitted with a $500 \mu \mathrm{L}$ gas-tight syringe (Hamilton, Reno, NV).

\section{Overview of IMS-MS Analysis}

A schematic diagram of the instrument used for this study is shown in Figure 1. The instrument is comprised of a standard electrospray source equipped with an hourglass ion funnel interface mounted to a drift tube/ time-of-flight-MS instrument that has been described elsewhere [33]. The drift tube assembly is made up of three drift tube regions that are connected in series by the use of ion funnels [34]. The instrument used for this study can be operated in many different modes that allow mobility selection, ion activation, and ion fragmentation to be coupled in the drift tube during a single IMS experiment by changing conditions at the funnels [35]. The drift tube conditions were set for transmission of all ions and analysis of the glycans in IMS-MS mode.

Briefly, experimental measurements are made as follows. Ions generated at the electrospray emitter are introduced directly into the source region where they are accumulated at the first ion funnel (F1). The accumulated ions are then pulsed as a narrow packet of ions (typically a $100 \mu$ s pulse width) into the first drift tube region (D1). The ions migrate through the drift tube region at their characteristic mobilities under the influence of a weak electric field and collide with He buffer gas at a pressure of $\sim 3$ Torr at $298 \mathrm{~K}$. As ions exit the first drift region, they enter ion funnel regions (F2, F3) that are used to focus the diffuse ion clouds and transmit species into successive drift regions (D2, D3).

Ions exit the drift tube through a differentially pumped region and are focused using ion optics into the main vacuum chamber. Drift time distribution of ions (without $m / z$ analysis) can be recorded using an on-axis collision dynode/microchannel plate detection system, or two-dimensional IMS-MS analysis can be performed by pulsing ions that exit into an orthogonal reflectron geometry time-of-flight MS. The MS analyzer has a typical resolving power of $\sim 4000$. The timescale of an ion mobility distribution for this study is about 70 $\mathrm{ms}$, while flight times in the MS require $65 \mu \mathrm{s}$. It is possible to perform many TOF experiments within a single drift experiment given the disparity in time scales. We refer to this as a "nested" experiment because MS flight time distributions are recorded within individual drift time windows. 


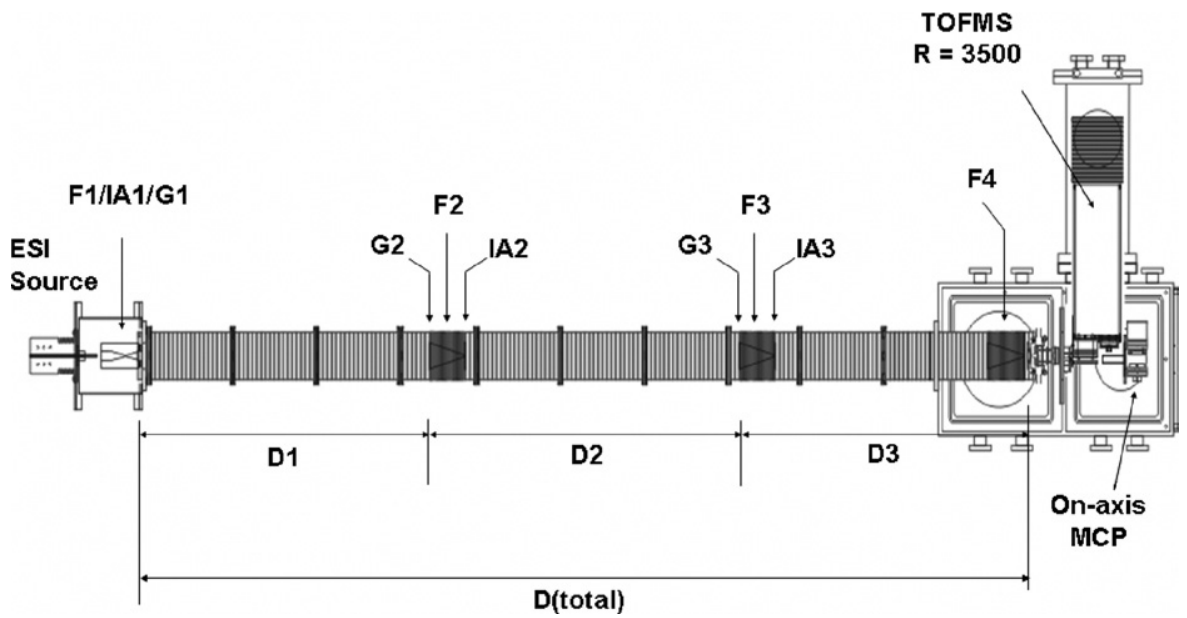

Figure 1. Schematic diagram of the IMS-TOF/MS instrument used. The modular drift tube design incorporates a drift region (D1-D3), ion gates (G2-G3), drift tube funnels (F2-F4), and ion activation regions (IA2-IA3). The drift tube conditions in this experiment were set to transmit all ions. See the Experimental section for details.

\section{Ion Source Conditions}

Ions are created by ESI and accumulated directly into a source funnel that is operated at $\sim 1$ to 3 Torr. The source funnel is designed to allow He from the drift tube to flow in the direction of the source, but this flow prevents ambient air from entering the drift region. Under the conditions of these experiments, we often find that glycan ions for individual $\mathrm{m} / \mathrm{z}$ values appear as broad peaks with few features in the IMS analysis. We believe this is because these ions may not be entirely desolvated before being gated into the drift region; or, multiple conformations may coexist, leading to broad peaks. In the analysis of glycans (as well as some other biomolecules) we find that in some cases the IMS distributions that are observed experimentally depend upon the source conditions (e.g., ESI needle voltage and position, solution composition, as well as fields used to trap ions in the funnel). In the present system, we have varied the source such that we observe sharp features in the IMS distributions. Two factors appear especially important: efficient formation of sodiated species (obtained by using $2 \mathrm{mM}$ sodium acetate in the sample solution); and, the RF fields in the source ion funnel. Under other conditions, the distributions may appear unresolved. This behavior, which is similar to that found upon heating the ion source, or injecting ions at high energies into a drift tube suggests that under these conditions, different conformations (present for the different isomers) anneal into more stable conformations before release into the drift tube. There is no evidence for fragmentation induced because of differences in source conditions. Once conditions where sharp peaks in the IMS distributions are observed, we find that it is possible to reproduce these features on different days (over several years that we have been examining these systems). We note that similar changes in ion distributions were observed early on in the analysis of protein ion conformations [36, 37].

\section{Experimental Mobilities and Cross Sections}

Drift time distributions for assigned glycans were used to obtain experimental cross sections. The details of determining cross sections using the modular drift tube have been described elsewhere [38]. Briefly, the time required for an ion to exit the drift region (drift time, $t_{D}$ ) is dependent on the mobility $(K)$ of the ion as given by the expression $K=\left(v_{D} \cdot E^{-1}\right)$ where $v_{D}$ is the drift velocity and $E$ is the drift field. The drift velocity of an ion is dependent on the overall charge state of the ion as well as its collision cross section. Ions with higher charge states typically have shorter drift times compared to ions having lower overall charge; similarly, ions of the same charge and mass with relatively compact structures have shorter drift times than those with more elongated structures. The drift time of an ion can be converted directly to a collision cross section by determining the reduced mobility (normalized to standard temperature and pressure) of the ion and according to the equation: [39]

$$
\Omega=\frac{(18 \pi)^{1 / 2}}{16} \frac{z e}{\left(k_{b} T\right)^{1 / 2}}\left[\frac{1}{m_{I}}+\frac{1}{m_{B}}\right]^{1 / 2} \frac{t_{d} E}{L} \frac{760}{P} \frac{T}{273.2} \frac{1}{N}
$$

where $\mathrm{L}, t_{d}$, and $E$ are the drift tube length, ion drift time, and drift field, respectively. $T$ and $P$ are the temperature and pressure of the buffer gas, respectively; $z e$ is the ion's charge; $m_{B}$ and $m_{I}$ are masses of buffer gas and ion of interest, respectively; $k_{b}$ is Boltzmann's constant; and $N$ is the neutral number density.

The cross section measurements of well-characterized systems are precise and usually fall within a $1 \%$ to $2 \%$ relative uncertainty $[35,40]$. The primary source of error with this type of measurement is usually associated with fluctuations in buffer gas temperature, which in our instrument varies with ambient temperature (and is recorded using a thermocouple that is attached to the drift tube can). 


\section{Molecular Dynamics of Select N-Linked Glycans}

Molecular dynamics simulations were performed on a series of glycans to compare experimentally derived cross sections to structures obtained from simulated annealing experiments. The molecular dynamics simulations were performed on a $300 \mathrm{MHz} \mathrm{O}_{2}$ SGI Unix workstation (Silicon Graphics, Inc., Mountain View, CA). Initial structures of $\left[\mathrm{H}_{3} \mathrm{~N}_{2}+2 \mathrm{Na}\right]^{2+}$ and three known isomers of $\left[\mathrm{H}_{5} \mathrm{~N}_{4}+2 \mathrm{Na}\right]^{2+}(\mathrm{H}=$ hexose, $\mathrm{N}=$ $\mathrm{N}$-acetylglucosamine) were constructed using the Insight II software package (Accelrys Inc., San Diego, CA) and followed by parameterization with the AMBER force field using Homans' carbohydrate parameters [41]. $\left[\mathrm{H}_{3} \mathrm{~N}_{2}+2 \mathrm{Na}\right]^{2+}$ structures were optimized (similar to procedures described previously) [42, 43] using the steepest descent and conjugate gradient minimization steps with tolerances of $10 \mathrm{kcal} \cdot \mathrm{mol}^{-1} \cdot \AA^{-1}$ and $0.01 \mathrm{kcal} \cdot \mathrm{mol}^{-1} \cdot \AA^{-1}$, respectively. Simulated annealing of the resulting structures were performed by running dynamics at $500 \mathrm{~K}$ for a period of $4 \mathrm{ps}$ followed by a cooling period to $298 \mathrm{~K}$ over $1 \mathrm{ps}$. Structures were then energy minimized as before and the resulting structures served as the input for the next round of annealing. $\left[\mathrm{H}_{5} \mathrm{~N}_{4}+2 \mathrm{Na}\right]^{2+}$ isomers were modeled using a modified protocol that uses restrained sodium ion distances at specific locations along the glycosidic and amide oxygens to probe a larger conformational space. A total of 11 charge configurations for each isomer were submitted for molecular dynamics at $298 \mathrm{~K}$ with sodium ions restrained to $2.3 \AA$ of amide or glycosidic oxygen atoms and sampled every 5 ps over a 0.25 ns simulation. Optimum sodium/oxygen distances were obtained from simulations of $\left[\mathrm{H}_{3} \mathrm{~N}_{2}+2 \mathrm{Na}\right]^{2+}$, which agreed with previously reported results that used higher levels of theory [44]. Low-energy conformations for each of these isomers were then subjected to a final stage of dynamics without restraints, resulting in 600 conformers and $3 \mathrm{~ns}$ of dynamics at $298 \mathrm{~K}$. Crosssections for trial geometries were calculated using the trajectory method (TM) or the projection approximation that has been calibrated to the TM method as described previously $[42,45]$.

\section{Results and Discussion}

\section{Nested $t_{D}(\mathrm{~m} / z)$ Profile of Ovalbumin Glycans}

Figure 2 (left) shows the nested IMS(MS) distribution [referred to as $t_{D}(m / z)$ dataset] for the PNGase F digest of ovalbumin. Examination of this distribution shows the dispersion of ions into different families as shown by the dashed lines. The mass spectra shown on the right of Figure 2 were obtained by integrating narrow regions along diagonal lines in the $t_{\mathrm{D}}(\mathrm{m} / \mathrm{z})$ dataset. The prominent features of the data include the $[\mathrm{M}+\mathrm{Na}]^{+}$ series and $[\mathrm{M}+2 \mathrm{Na}]^{2+}$ series as shown in slices a and b. The +2 series is the most intense feature of the dataset. Ions in this series correspond to high mannose and hybrid class glycans that include $\left[\mathrm{H}_{5} \mathrm{~N}_{2}+2 \mathrm{Na}\right]^{2+}$ at $m / z=801.40,\left[\mathrm{H}_{6} \mathrm{~N}_{2}+2 \mathrm{Na}\right]^{2+}$ at $m / z=903.45$, and $\left[\mathrm{H}_{5} \mathrm{~N}_{4}+2 \mathrm{Na}\right]^{2+}$ at $\mathrm{m} / \mathrm{z}=1046.52(\mathrm{H}=$ hexose, $\mathrm{N}=$ $\mathrm{N}$-acetylglucosamine).

The +1 series is shown in diagonal slice a with the sodiated trimannosyl glycan core $\left[\mathrm{H}_{3} \mathrm{~N}_{2}+\mathrm{Na}\right]^{+}$at $m / z=1171.50$, and chitobiose glycan core with two mannose residues $\left[\mathrm{H}_{2} \mathrm{~N}_{2}+\mathrm{Na}\right]^{+}$at $\mathrm{m} / z=966.59$ readily observed with lower $\mathrm{m} / \mathrm{z}$ species found in higher abundance. Higher charge states for the N-linked glycans were not observed in this experiment, but a series of multiply charged multimers were seen in the high mobility region and shown in diagonal slice $d$. The ions extracted in region $c$ of the $t_{D}(m / z)$ dataset have sharp drift time distributions and have been tentatively assigned to by-products of the permethylation reaction and sodium adducts based on the $\mathrm{m} / \mathrm{z}$ range and spacing observed for these series of $[\mathrm{M}+2 \mathrm{Na}]^{2+}$ ions.

\section{Mobility Separations Reduce Spectral Congestion of Glycan Mixtures}

A closer inspection of the $t_{\mathrm{D}}(\mathrm{m} / \mathrm{z})$ dataset also demonstrates the ability to shift lower abundance species into regions with lower chemical noise as illustrated in Figure 3. This is similar to what has been reported for complex mixtures of peptides using these techniques $[46,47]$. The bottom inset of Figure 3 shows an expanded view of the +2 series integrated along a diagonal slice from $m / z=500$ to 1350 . This region of the IMS-MS dataset is dominated by the $[\mathrm{M}+2 \mathrm{Na}]^{2+}$ series of N-linked glycans and range in size from the trimannosyl glycan core $(\mathrm{m} / \mathrm{z}=597.30)$ to $\left[\mathrm{H}_{3} \mathrm{~N}_{8}+\right.$ $2 \mathrm{Na}]^{2+}(m / z=1332.67)$. In this region of the dataset, 18 out of 19 different $\mathrm{m} / \mathrm{z}$ assignments corresponding to $\mathrm{N}$-linked glycans have been made. These assignments are summarized in Table 1.

Also similar to peptide ion mixtures, mass spectra that are obtained by taking slices across diagonal regions show the separation of charge state families. For example, Figure 3 shows regions corresponding to a +1 series (left) and +2 series (right) (these regions have been magnified for the $\mathrm{m} / \mathrm{z}$ range of 950 to 1200 at the top of Figure 3). The ions for $\left[\mathrm{H}_{2} \mathrm{~N}_{2}+\mathrm{Na}\right]^{+}(\mathrm{m} / \mathrm{z}=$ 967.49) and $\left[\mathrm{H}_{3} \mathrm{~N}_{2}+\mathrm{Na}\right]^{+}(\mathrm{m} / z=1171.59)$ ions have been clearly separated from the $\left[\mathrm{H}_{3} \mathrm{~N}_{5}+2 \mathrm{Na}\right]^{2+}(\mathrm{m} / \mathrm{z}=$ 964.99) and $\left[\mathrm{H}_{5} \mathrm{~N}_{5}+2 \mathrm{Na}\right]^{2+}(m / z=1169.09)$ ions using a mobility separation before mass analysis.

\section{Example Drift Time (Cross Section) Distributions}

Figure 4 shows IMS profiles for two N-linked glycans, selected as examples. These are plotted on a cross section scale $\left(200 \AA^{2}\right.$ to $\left.500 \AA^{2}\right)$ obtained using an extracted drift time profile and eq 1 . The drift time distribution for Man $3\left(\left[\mathrm{H}_{3} \mathrm{~N}_{2}+2 \mathrm{Na}\right]^{2+}, m / z=597.3\right)$ shows a sharp peak centered at $264.1 \AA^{2}$ corresponding to the glycan core, which is present in all N-linked 


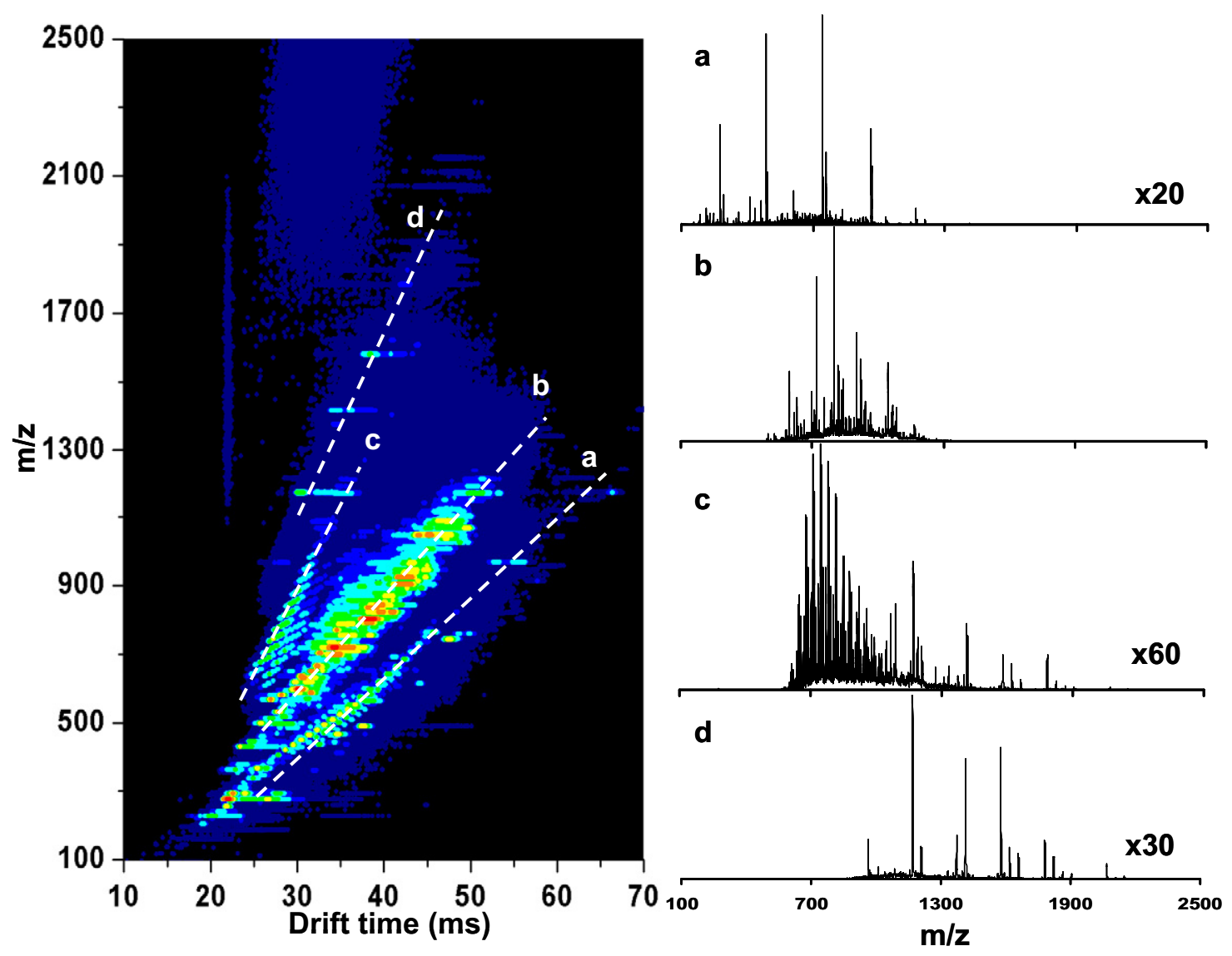

\begin{abstract}
Figure 2. The two-dimensional $t_{D}(\mathrm{~m} / \mathrm{z})$ false color plot on the left shows the drift time $(\mathrm{ms}$, bottom axis) and mass to charge $(\mathrm{m} / \mathrm{z}$, left axis) distribution of $\mathrm{N}$-linked glycans from ovalbumin. The sodiated species of glycans dominate where the $[\mathrm{M}+\mathrm{Na}]^{+}$family can be extracted by integrating along a diagonal line labeled a (white dash). The dashed line $b$ indicates the positions of the $[\mathrm{M}+2 \mathrm{Na}]^{2+}$ charge state family. Diagonal slice c represents a +2 charge state family of species within the mass range of $\mathrm{N}$-linked glycans showing a spacing equivalent to a methylene group $(\Delta \mathrm{m}=14 \mathrm{amu})$ corresponding to partially permethylated ions. Multimeric species are extracted along the diagonal slice $\mathrm{d}$ in the high mobility regions of the $\mathrm{t}_{\mathrm{D}}(\mathrm{m} / \mathrm{z})$ dataset.
\end{abstract}

glycans. We note that although this peak is sharp there are some reproducible shoulders corresponding to ions having different structure that are not entirely resolved; also observed is a much smaller feature $(<5 \%$ abundance for this $\mathrm{m} / \mathrm{z}$ ) corresponding to ions with larger cross sections. However, overall this profile is consistent with a distribution that is expected to be dominated by a single isomer. As we gain experience with glycans, we are finding that the observation of lower abundance features in distributions that are expected to correspond to single isomers is not atypical. It may be that a single isomer exists as multiple conformations; or another ion having a different covalent structure may be present in low abundance. In general, though, ions that are expected to show only a single isomer are normally dominated by one large sharp peak and other features appear smaller.

On the other hand, IMS distributions for $\mathrm{m} / \mathrm{z}$ ranges that are expected to contain multiple isomers often exhibit more complicated behavior. The top panel of Figure 4 shows the drift time distribution of $\left[\mathrm{H}_{5} \mathrm{~N}_{4}+\right.$
$2 \mathrm{Na}]^{2+}(m / z=1046.52)$, which is a hybrid-type glycan known to occur in ovalbumin and have multiple isomers. The structures of $\left[\mathrm{H}_{5} \mathrm{~N}_{4}+2 \mathrm{Na}\right]^{2+}$ isomers, which were reported previously based on tandem MS results $[48,49]$, are shown on the top left of Figure 4 . The drift time distribution for $\left[\mathrm{H}_{5} \mathrm{~N}_{4}+2 \mathrm{Na}\right]^{2+}$ shows three resolved peaks centered at cross sections of $382.1 \AA^{2}$, $392.2 \AA^{2}$, and $411.8 \AA^{2}$, respectively. Using peak heights, we estimate the intensity ratios of these peaks to be 1:1.5:0.8, respectively. Alternatively, we have also fit peaks using Gaussian peak shapes (and subtracted these fits to estimate abundances). Using this approach, the relative ratios of peak areas are estimated to range from $\sim 1: 1.35: 0.85$ to $\sim 1: 1.5: 0.8$; the range provides some feeling of the anticipated uncertainty in these relative abundances.

Table 1 also provides a summary of the number of distinct features for each $\mathrm{m} / \mathrm{z}$ ion as well as experimentally derived cross sections. A total of $42[\mathrm{M}+2 \mathrm{Na}]^{2+}$ species are observed for this series of ions. Although smaller N-linked glycans have drift time distributions 


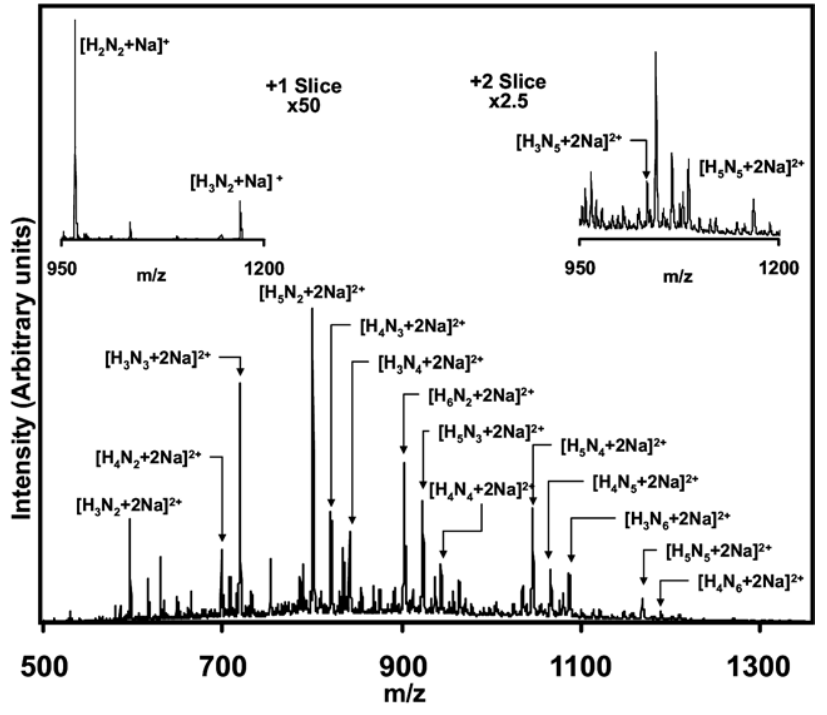

Figure 3. The mass spectrum obtained by integrating the +2 family is shown above. The labels correspond to assignments made for selected $\mathrm{N}$-linked glycans observed in the direct infusion experiment. The inset on the top left shows the assignment of two $\mathrm{N}$-linked glycans $\left(\left[\mathrm{H}_{2} \mathrm{~N}_{2}+\mathrm{Na}\right]^{+}\right.$and $\left.\left[\mathrm{H}_{3} \mathrm{~N}_{2}+\mathrm{Na}\right]^{+}\right)$in the +1 family that have similar $m / z$ values to $\mathrm{N}$-linked glycans observed in the +2 family $\left(\left[\mathrm{H}_{3} \mathrm{~N}_{5}+2 \mathrm{Na}\right]^{2+}\right.$ and $\left[\mathrm{H}_{5} \mathrm{~N}_{5}+2 \mathrm{Na}\right]^{2+}$, top right inset). ( $\mathrm{H}=$ hexose, $\mathrm{N}=\mathrm{N}$-acetylglucosamine).

that resemble Man $3\left(\left[\mathrm{H}_{3} \mathrm{~N}_{2}+2 \mathrm{Na}\right]^{2+}\right)$, possibly other conformations of these oligosaccharides exist. Since the enzymatic release of N-glycans result in the formation of structures with free reducing end, exchange between the $\alpha$ and $\beta$ forms of the reducing end $\mathrm{N}$-acetylglucosamine could contribute to multiple peaks in the drift time distribution [25].

\section{Molecular Modeling and Cross Sections for Calculated Trial Geometries of Different Isomers}

It is interesting to examine molecular dynamics simulations of $\left[\mathrm{H}_{3} \mathrm{~N}_{2}+2 \mathrm{Na}\right]^{2+}$ and three isomers of $\left[\mathrm{H}_{5} \mathrm{~N}_{4}+\right.$ $2 \mathrm{Na}]^{2+}$. As discussed previously [50-52], correlation between low-energy trial conformations and sharp features in the drift time distribution provides a possible means of assigning isomers. This approach has significant merit in complementing fragmentation studies. Lowest energy conformers (10 lowest calculated energies) for $\left[\mathrm{H}_{3} \mathrm{~N}_{2}+2 \mathrm{Na}\right]^{2+}$ have a calculated cross section of $269.9 \pm 3.08 \AA^{2}$, within $2.2 \%$ (relative uncertainty) of the experimental cross section of $264.1 \AA^{2}$ measured for the large sharp feature. Automatic assignment of partial charges using Homans' carbohydrate parameters [41] listed partial charges in increasing order for oxygens as: glycosidic (anomeric) < acyl < methoxy oxygens. Inspection of $\mathrm{Na}^{+} \rightarrow \mathrm{O}$ distances for the geometries generated during the simulation is beneficial, since these atoms would likely drive energetically favorable interactions with noncovalent sodium ions and have a large influence on the gas-phase conformations [28, 44]. A comparison of $\mathrm{Na}^{+} \rightarrow \mathrm{O}$ distances for lowest energy conformations of the simulation revealed that the $\mathrm{Na}^{+}$ ions were relatively immobile, with an average distance of $2.33 \pm 0.01 \AA$. Interestingly, analysis of all torsion angles $(\phi, \psi, \omega)$ showed small changes as well for these low-energy conformations, the largest of which was the torsion angle $\phi$ for the 1-3 glycosidic bond between the $\alpha$ mannose and beta mannose of the core [ $\alpha$-D-Manp$(1 \rightarrow 3)$ - $\beta$-D-Manp $\left( \pm 1.2^{\circ}\right)$ ] representing periodically sampled structures that are similar in conformation and energy. The similarities in geometry and cross section between the lowest energy conformations extracted at different points during the simulation $(\sim 0.15 \mathrm{~ns}$ through $0.5 \mathrm{~ns}$ ) indicate a large sampling of conformational space given the overall spread in cross sections throughout the dynamics run.

Analysis of 9-residue oligosaccharide $\left[\mathrm{H}_{7} \mathrm{~N}_{2}+2 \mathrm{Na}\right]^{2+}$ ions showed much smaller relative cross section changes throughout the simulation, even when performing dynamics at elevated temperatures (1000 and $1500 \mathrm{~K}$, data not shown). This result agreed with a previous report, suggesting the small effect that higher energies (i.e., higher temperatures) used in the simulation had on $\mathrm{Na}^{+}$positions in more complex glycan structures [44].

Figure 5 shows a scatter plot of cross sections vs. total energy for three isomers of $\left[\mathrm{H}_{5} \mathrm{~N}_{4}+2 \mathrm{Na}\right]^{2+}$. It is interesting that each of the glycans may exist over a range of cross sections, depending upon the site assignments of charges and the specific ion conformation. However, the analysis does provide clues about the assignments of different experimental features that are observed. To find model structures that had cross sections that were similar to the experimental values, we employed a simulated annealing approach. Annealing of a large group of preliminary glycan ion structures was carried out by restraining sodium ions to a distance of $2.33 \AA$ at all glycosidic and amide oxygens (shown as open diamonds in the bottom part of Figure 5). The lowest energy conformation of each of these isomers was then run through a second round of molecular dynamics at $298 \mathrm{~K}$ (shown as closed diamonds). One issue that arises in this type of analysis is which conformers for each isomer should be compared with experiment. Typically one uses the lowest energy conformers, or a set of low-energy structures (in an attempt to find an average type of conformation that is representative of experiment). In the modeling approach that we have used, the lowest energy structure for each of the three isomers of $\left[\mathrm{H}_{5} \mathrm{~N}_{4}+2 \mathrm{Na}\right]^{2+}$ yielded calculated cross sections of $381.7,392.9$, and $415.0 \AA^{2}$. If we were to select the three lowest energy conformers for each isomer (in this case the lowest three fall within 0.2 $\mathrm{kcal} / \mathrm{mol}$ of one another) we obtain average cross sections of $382.1 \pm 0.9,392.9 \pm 1.3$, and $414.2 \pm 1.1 \AA^{2}$. This selection leads to the same assignment of peaks. We note that selection of the 10 lowest energy structures for each results in cross sections of $382.4 \pm 1.2,393.9 \pm$ 2.1, $417.9 \pm 3.7 \AA^{2}$. Although the range of energies associated with these structures is 0.5 to $3.1 \mathrm{kcal} / \mathrm{mol}$, the assignment of peaks would not vary. We note that 


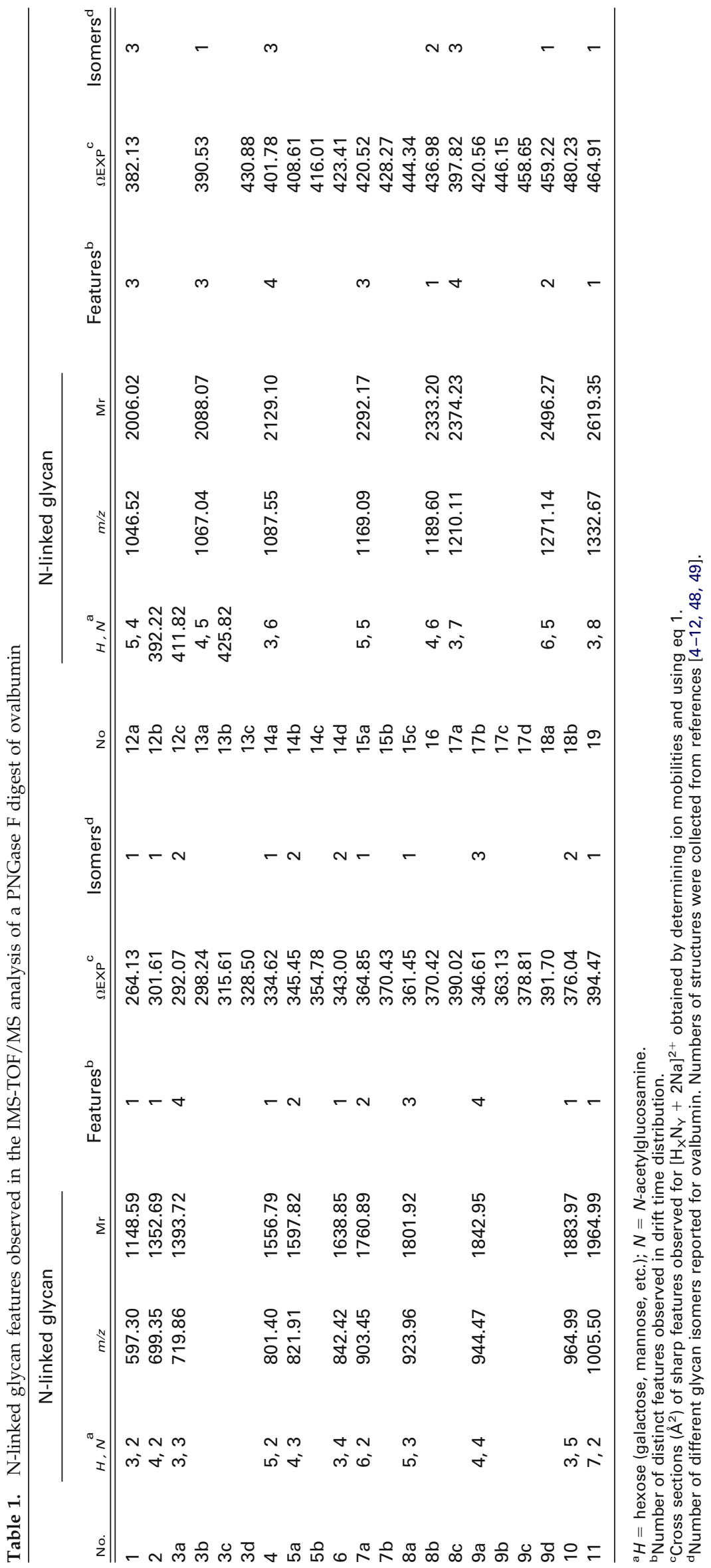


in all cases, the selection of lowest energy structures is associated with one of the charge site assignments that were used to model the conformations.

We find average calculated cross sections of $382.4 \pm$ $1.2 \AA^{2}$ for the tetra-antennary N-linked glycan shown in blue, $393.9 \pm 2.1 \AA^{2}$ for the tri-antennary N-linked glycan with a bisecting $N$-acetylglucosamine (GlcNAc) shown in red, and $417.9 \pm 3.7 \AA^{2}$ for the biantennary structure with a bisecting GlcNAc shown in black. These calculated cross sections for the lowest energy calculated structures for each of these three isomers were all within $1.5 \%$ of the experimentally observed features for this N-linked glycan. From this, we have made the assignments of the three structures that are shown in Figure 5.

Finally, Figure 6 shows representation of the structures of different isomers. Each structure that is shown corresponds to the lowest energy conformer found by molecular dynamics for each of three isomers of $\left[\mathrm{H}_{5} \mathrm{~N}_{4} \mathrm{a}-\mathrm{c}+2 \mathrm{Na}\right]^{2+}$. The carbons on the $3^{\prime}$ antennae on all structures and bisecting GlcNAc residues on structures $\left[\mathrm{H}_{5} \mathrm{~N}_{4} \mathrm{~b}\right]$ and $\left[\mathrm{H}_{5} \mathrm{~N}_{4} \mathrm{c}\right]$ are shown in green. Interestingly, the folding of the $6^{\prime}$ antennae over the chito-

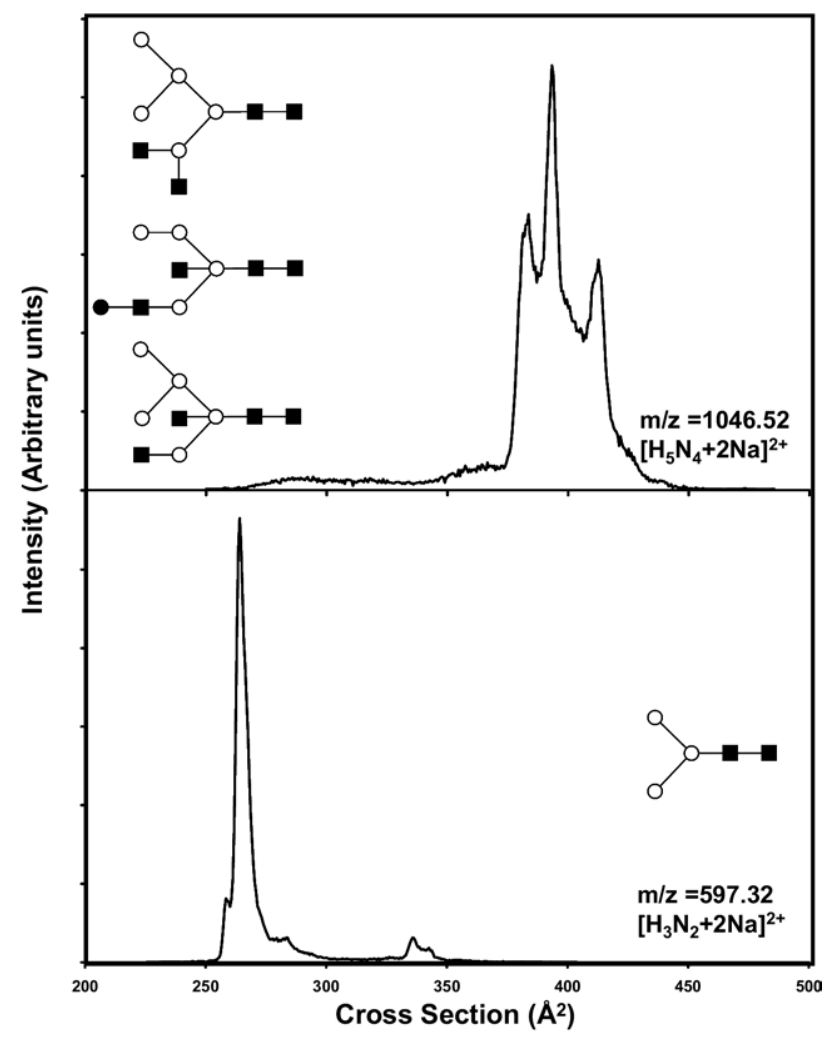

Figure 4. Drift time distributions of selected N-linked glycans plotted on a cross section scale $\left(\AA^{2}\right)$. Three sharp peaks are present for the top distribution at $\mathrm{m} / \mathrm{z}=1046.52$ corresponding to $\left[\mathrm{H}_{5} \mathrm{~N}_{4}+2 \mathrm{Na}\right]^{2+}$ for which three isomers have been reported and having cross sections centered at $382.1 \AA^{2}, 392.2 \AA^{2}$, and $411.8 \AA^{2}$, respectively. The bottom drift time distribution corresponds to the $m / z$ value for $\left[\mathrm{H}_{3} \mathrm{~N}_{2}+2 \mathrm{Na}\right]^{2+}$ with a sharp peak centered at 264.1 $\AA^{2}$. [N = (filled square) $N$-acetylglucosamine, $\mathrm{H}=$ hexoses, (open circle $)=$ mannose $($ filled circle $)=$ galactose $]$.

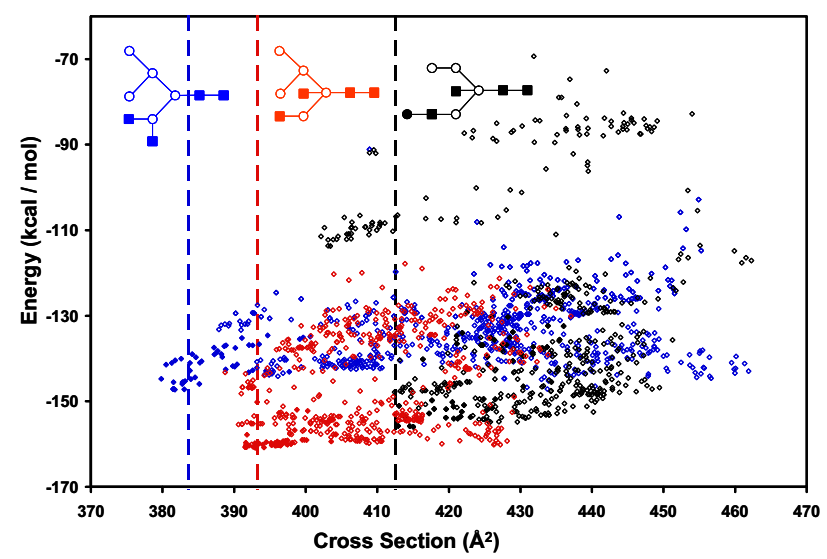

Figure 5. Calculated cross sections $\left(\AA^{2}\right.$ and energies $\left(\mathrm{kcal} \cdot \mathrm{mol}^{-1}\right)$ from molecular modeling simulations with assignments for three isomers of $\left[\mathrm{H}_{5} \mathrm{~N}_{4}+2 \mathrm{Na}\right]^{2+}$. Cross sections were calculated for minimized structures obtained after each successive step of annealing using the trajectory method (see the Experimental section for details). Experimental cross sections for three sharp features are shown by dashed lines. Structure (a) is represented by blue diamonds, structure $(\mathbf{b})$ is represented by red diamonds, and data obtained for structure (c) is shown in black. $\left[\mathrm{H}_{5} \mathrm{~N}_{4}\right.$ a: $382.4 \AA^{2}$, $\mathrm{H}_{5} \mathrm{~N}_{4}$ b: $393.9 \AA^{2}, \mathrm{H}_{5} \mathrm{~N}_{4} \mathrm{c}: 417.9 \AA^{2}$ ].

biose core is a common feature of the lowest energy conformations. Structures with this configuration also lead to the more compact geometries (and lowest energies) observed during the MD simulations. The isomer with the smallest cross section, $\left[\mathrm{H}_{5} \mathrm{~N}_{4} \mathrm{a}\right]$, appears to favor geometries that allow interactions between a highly branched $3^{\prime}$ antennae with $\mathrm{Na}^{+}$ions and the core. The N-linked glycans with larger cross sections, $\left[\mathrm{H}_{5} \mathrm{~N}_{4} \mathrm{~b}-\mathrm{c}\right]$, do not show this behavior and retain more elongated $3^{\prime}$ antennae that interact with $\mathrm{Na}^{+}$ions that are distant from chitobiose core.
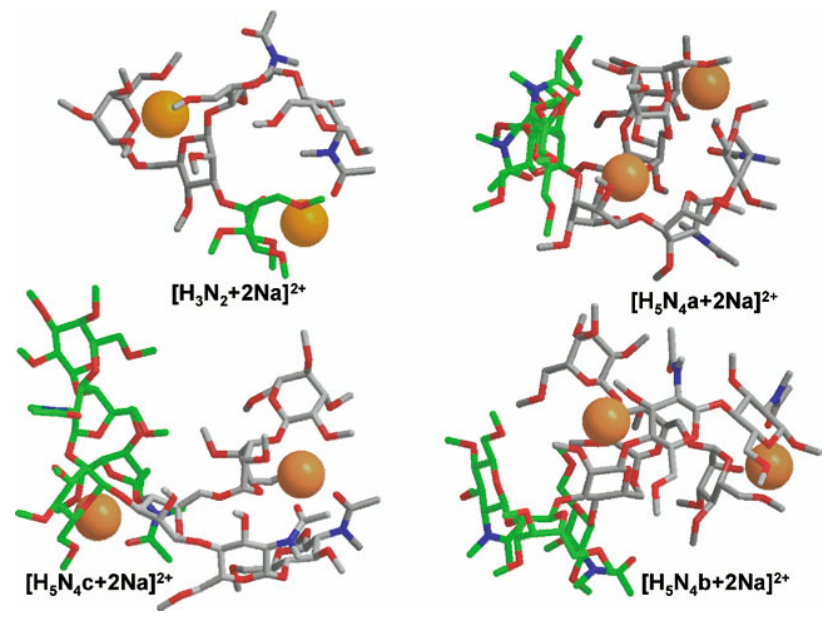

Figure 6. Representative structures for low-energy conformations of modeled N-linked glycans. Low-energy conformations for $\left[\mathrm{H}_{3} \mathrm{~N}_{2}+2 \mathrm{Na}\right]^{2+}$ and three isomers of $\left[\mathrm{H}_{5} \mathrm{~N}_{4}+2 \mathrm{Na}\right]^{2+}$ that agree with experimentally determined cross sections are shown (clockwise from top left: $\mathrm{H}_{3} \mathrm{~N}_{2}, \mathrm{H}_{5} \mathrm{~N}_{4} \mathrm{~A}, \mathrm{H}_{5} \mathrm{~N}_{4} \mathrm{~B}, \mathrm{H}_{5} \mathrm{~N}_{4} \mathrm{C}$ ). Carbons on bisecting GlcNAc and the $\alpha 1-3$ mannose branch are shown in green to improve clarity. 


\section{Conclusions}

The characterization of ovalbumin hybrid and highmannose N-linked glycans was performed using a nanoflow ESI-IMS-TOF/MS approach. This first analysis shows that IMS is highly complementary to MS for the analysis of isomers. We found evidence for 42 distinct features that correspond to $19 \mathrm{~m} / \mathrm{z}$ values consistent with natriated $\mathrm{N}$-linked glycans associated with ovalbumin for the $[\mathrm{M}+2 \mathrm{Na}]^{2+}$ series and a limited number of less intense $[\mathrm{M}+\mathrm{Na}]^{+}$species (Man3 and smaller). Drift time distributions were used to obtain experimental cross sections for some features. Four glycans were analyzed in more detail by molecular modeling techniques. For these, trial structures were taken through an energy minimization process and cross sections were calculated for a range of ions that were obtained from dynamics. Using this information, it was possible to make assignments of three peaks to one isomer set of structures that have been reported previously.

At this point, the ability to pull apart different ions that have different structures by IMS has been demonstrated. Moreover, an example for separating and assigning three different isomers shows that combining IMS-MS analysis with molecular modeling appears promising. However, while promising, there is ambiguity associated with what has been separated by IMS and the methodology for detailed characterization is clearly at an early stage. Because a single isomer may exist as multiple conformations that may not be in equilibrium in the gas phase, the IMS separation may show multiple features for individual isomers. We have attempted to minimize the overlap of conformations from different isomers by operating our source under conditions that we believe should allow different conformations to anneal into preferred states before they are separated in the drift tube. In these cases, we have shown that this approach appears to be a promising method to assign structural isomers. However, more work is needed to develop methods for clearly discerning between conformers and isomers in these studies. Multidimensional IMS-MS analysis is a promising approach that can be used to assign features in the drift time profiles to a particular isomer or conformer [53]. In addition to the present methodology, this approach can be useful for the analysis of glycan heterogeneity. Several other approaches are also under development, including coupling condensed phase separations with IMS-MS methods, which should allow those isomers that are separable before ionization to be characterized, and MS/MS analysis after IMS separations.

\section{Acknowledgments}

The authors acknowledge support for this work by the National Center for Glycomics and Glycoproteomcis under grant number RR018942 through the National Institute of Health (NIH) within the National Center for Research Resources (NCRR).

\section{References}

1. Varki, A. Biological Roles of Oligosaccharides-All of the Theories are Correct. Glycobiology 1993, 3, 97-130.

2. Bertozzi, C. R.; Kiessling, L. L. Chemical Glycobiology. Science 2001, 291, 2357-2364.

3. Dennis, J. W.; Granovsky, M.; Warren, C. E. Protein Glycosylation in Development and Disease. Bioessays 1999, 21, 412-421.

4. Kornfeld, R.; Kornfeld, S. Assembly of Asparagine-Linked Oligosaccharides. Annu. Rev. Biochem. 1985, 54, 631-664.

5. Huntington, J. A.; Stein, P. E. Structure and Properties of Ovalbumin. J. Chromatogr. B 2001, 756, 189-198.

6. Harvey, D. J.; Wing, D. R.; Kuster, B.; Wilson, I. B. H. Composition of N-Linked Carbohydrates from Ovalbumin and Copurified Glycoproteins. J. Am. Soc. Mass Spectrom. 2000, 11, 564-571.

7. Yamashita, K.; Kamerling, J. P.; Kobata, A. Structural Study of the Carbohydrate Moiety of Hen Ovomucoid-Occurrence of a Series of Penta-Antennary Complex-Type Asparagine-Linked Sugar Chains. J. Biol. Chem. 1982, 257, 2809-2814.

8. Yamashita, K.; Kamerling, J. P.; Kobata, A. Structural Studies of the Sugar Chains of Hen Ovomucoid-Evidence Indicating That They Are Formed Mainly by the Alternate Biosynthetic Pathway of AsparagineLinked Sugar Chains. J. Biol. Chem. 1983, 258, 3099-3106.

9. Yamashita, K.; Tachibana, Y.; Hitoi, A.; Kobata, A. Sialic Acid-Containing Sugar Chains of Hen Ovalbumin and Ovomucoid. Carbohydr. Res. 1984, 130, 271-288.

10. Yamashita, K.; Tachibana, Y.; Kobata, A. Structures of GalactoseContaining Sugar Chains of Ovalbumin. J. Biol. Chem. 1978, 253, 3862-3869.

11. Yamashita, K.; Ueda, I.; Kobata, A. Sulfated Asparagine-Linked Sugar Chains of Hen Egg Albumin. J. Biol. Chem. 1983, 258, 4144-4147.

12. Mao, X. L.; Wang, K.; Du, Y. G.; Lin, B. C. Analysis of Chicken and Turkey Ovalbumins by Microchip Electrophoresis Combined with Exoglycosidase Digestion. Electrophoresis 2003, 24, 3273-3278.

13. Madera, M.; Mechref, Y.; Novotny, M. V. Combining Lectin Microcolumns with High-Resolution Separation Techniques for Enrichment of Glycoproteins and Glycopeptides. Anal. Chem. 2005, 77, 4081-4090.

14. Mechref, Y.; Novotny, M. V. Structural Investigations of Glycoconjugates at High Sensitivity. Chem. Rev. 2002, 102, 321-369.

15. Zaia, J. Mass Spectrometry of Oligosaccharides. Mass Spectrom. Rev. 2004, 23, 161-227.

16. Mechref, Y.; Kang, P.; Novotny, M. V. Differentiating Structural Isomers of Sialylated Glycans by Matrix-Assisted Laser Desorption/Ionization Time-of-Flight/Time-of-Flight Tandem Mass Spectrometry. Rapid Commun. Mass Spectrom. 2006, 20, 1381-1389.

17. Mechref, Y.; Novotny, M. V.; Krishnan, C. Structural Characterization of Oligosaccharides Using MALDI-TOF/TOF Tandem Mass Spectrometry. Anal. Chem. 2003, 75, 4895-4903.

18. Valentine, S. J.; Liu, X. Y.; Plasencia, M. D.; Hilderbrand, A. E.; Kurulugama, R. T.; Koeniger, S. L.; Clemmer, D. E. Developing Liquid Chromatography Ion Mobility Mass Spectrometry Techniques. Expert Rev. Proteom. 2005, 2, 553-565.

19. Koeniger, S. L.; Valentine, S. J.; Myung, S.; Plasencia, M.; Lee, Y. J.; Clemmer, D. E. Development of Field Modulation in a Split-Field Drift Tube for High-Throughput Multidimensional Separations. J. Proteome Res. 2005, 4, 25-35.

20. Sowell, R. A.; Koeniger, S. L.; Valentine, S. J.; Moon, M. H.; Clemmer, D. E. Nanoflow LCIMS-MS and LCIMS-CID/MS of Protein Mixtures. J. Am. Soc. Mass Spectrom. 2004, 15, 1341-1353.

21. Wu, C.; Siems, W. F.; Klasmeier, J.; Hill, H. H. Separation of Isomeric Peptides Using Electrospray Ionization/High-Resolution Ion Mobility Spectrometry. Anal. Chem. 2000, 72, 391-395.

22. McLean, J. A.; Ruotolo, B. T.; Gillig, K. J.; Russell, D. H. Ion MobilityMass Spectrometry: A New Paradigm for Proteomics. Int. J. Mass Spectrom. 2005, 240, 301-315.

23. Jarrold, M. F. Peptides and Proteins in the Vapor Phase. Annu. Rev. Phys. Chem. 2000, 51, 179-207.

24. Jin, L.; Barran, P. E.; Deakin, J. A.; Lyon, M.; Uhrin, D. Conformation of Glycosaminoglycans by Ion Mobility Mass Spectrometry and Molecular Modeling Phys. Chem. Chem. Phys. 2005, 7, 3464-3471.

25. Clowers, B. H.; Dwivedi, P.; Steiner, W. E.; Hill, H. H.; Bendiak, B Separation of Sodiated Isobaric Disaccharides and Trisaccharides Using Electrospray Ionization-Atmospheric Pressure Ion Mobility-Time of Flight Mass Spectrometry. J. Am. Soc. Mass Spectrom. 2005, 16, 660-669.

26. Clowers, B. H.; Hill, H. H. Mass Analysis of Mobility-Selected Ion Populations Using Dual Gate, Ion Mobility, Quadrupole Ion Trap Mass Spectrometry. Anal. Chem. 2005, 77, 5877-5885.

27. Gabryelski, W.; Froese, K. L. Rapid and Sensitive Differentiation of Anomers, Linkage, and Position Isomers of Disaccharides Using HighField Asymmetric Waveform Ion Mobility Spectrometry (FAIMS). J. Am. Soc. Mass Spectrom. 2003, 14, 265-277.

28. Lee, S.; Wyttembach, T.; Bowers, M. T. Gas-Phase Structures of Sodiated Oligosaccharides by Ion Mobility Ion Chromatography Methods. Int. J. Mass Spectrom. 1997, 167/168, 605-614.

29. Mechref, Y.; Novotny, M. V. Mass Spectrometric Mapping and Sequencing of N-linked Oligosaccharides Derived from Submicrogram Amounts of Glycoproteins. Anal. Chem. 1998, 70, 455-463. 
30. Ciucanu, I.; Costello, C. E. Elimination of Oxidative Degradation During the per-O-Methylation of Carbohydrates. J. Am. Chem. Soc. 2003, 125, 16213-16219.

31. Kang, P.; Mechref, Y.; Klouckova, I.; Novotny, M. V. Solid-Phase Permethylation of Glycans for Mass Spectrometric Analysis. Rapid Commun. Mass Spectrom. 2005, 19, 3421-3428.

32. Kang, P.; Mechref, Y.; Novotny, M. V. High-Throughput Solid-Phase permethylation of Glycans Prior to Mass Spectrometry. Rapid Commun. Mass Spectrom. 2008, 22, 721-734.

33. Merenbloom, S. I.; Koeniger, S. L.; Valentine, S. J.; Plasencia, M. D.; Clemmer, D. E. IMS-IMS and IMS-IMS-IMS/MS for Separating Peptide and Protein Fragment Ions. Anal. Chem. 2006, 78, 2802-2809.

34. Tang, K.; Shvartsburg, A. A.; Lee, H. N.; Prior, D. C.; Buschbach, M. A.; Li, F. M.; Tolmachev, A. V.; Anderson, G. A.; Smith, R. D. HighSensitivity Ion Mobility Spectrometry/Mass Spectrometry Using Electrodynamic Ion Funnel Interfaces. Anal. Chem. 2005, 77, 3330-3339.

35. Koeniger, S. L.; Merenbloom, S. I.; Valentine, S. J.; Jarrold, M. F.; Udseth, H. R.; Smith, R. D.; Clemmer, D. E. An IMS-IMS Analogue of MS-MS. Anal. Chem. 2006, 78, 4161-4174.

36. Valentine, S. J.; Counterman, A. E.; Clemmer, D. E. Conformer-Dependent Proton-Transfer Reactions of Ubiquitin Ions. J. Am. Soc. Mass Spectrom. 1997, 8, 954-961.

37. Li, J. W.; Taraszka, J. A.; Counterman, A. E.; Clemmer, D. E. Influence of Solvent Composition and Capillary Temperature on the Conformations of Electrosprayed Ions: Unfolding of Compact Ubiquitin Conformers from Pseudonative and Denatured Solutions. Int. J. Mass Spectrom. 1999, 187, 37-47.

38. Koeniger, S. L.; Merenbloom, S. I.; Clemmer, D. E. Evidence for Many Resolvable Structures Within Conformation Types of Electrosprayed Ubiquitin Ions. J. Phys. Chem. B 2006, 110, 7017-7021.

39. Mason, E. A.; McDaniel, E. W. Transport Properties of Ions in Gases; Wiley: New York, 1988;137-216.

40. Thalassinos, K.; Slade, S. E.; Jennings, K. R.; Scrivens, J. H.; Giles, K.; Wildgoose, J.; Hoyes, J.; Bateman, R. H.; Bowers, M. T. Ion Mobility Mass Spectrometry of Proteins in a Modified Commercial Mass Spectrometer. Int. J. Mass Spectrom. 2004, 236, 55-63.

41. Homans, S. W. A Molecular Mechanical Force-Field for the Conformational Analysis of Oligosaccharides: Comparison of Theoretical and Crystal Structures of man- $\alpha 1-3$ man- $\beta 1-4$ glcnac. Biochemistry 1990, 29 , 9110-9118.
42. Counterman, A. E.; Clemmer, D. E. Volumes of Individual Amino Acid Residues in Gas-Phase Peptide Ions. J. Am. Chem. Soc. 1999, 121, 4031-4039.

43. Counterman, A. E.; Clemmer, D. E. Cis-Trans Signatures of ProlineContaining Tryptic Peptides in the Gas Phase. Anal. Chem. 2002, 74 1946-1951.

44. Fukui, K.; Kameyama, A.; Mukai, Y.; Takahashi, K.; Ikeda, N.; Akiyama, Y.; Narimatsu, H. A Computational Study of Structure-Reactivity Relationships in Na-Adduct Oligosaccharides in Collision-Induced Dissociation Reactions. Carbohydr. Res. 2006, 341, 624-633.

45. Wyttenbach, T.; vonHelden, G.; Batka, J. J.; Carlat, D.; Bowers, M. T. Effect of the Long-Range Potential on Ion Mobility Measurements. J. Am. Soc. Mass Spectrom. 1997, 8, 275-282.

46. Valentine, S. J.; Counterman, A. E.; Hoaglund, C. S.; Reilly, J. P. Clemmer, D. E. Gas-Phase Separations of Protease Digests. I. Am. Soc. Mass Spectrom. 1998, 9, 1213-1216.

47. Henderson, S. C.; Valentine, S. J.; Counterman, A. E.; Clemmer, D. E. ESI/Ion Trap/Ion Mobility/Time-of-Flight Mass Spectrometry for Rapid and Sensitive Analysis of Biomolecular Mixtures. Anal. Chem. 1999, 71, 291-301.

48. Lattova, E.; Snovida, S.; Perreault, H.; Krokhin, O. Influence of the Labeling Group on Ionization and Fragmentation of Carbohydrates in Mass Spectrometry. J. Am. Soc. Mass Spectrom. 2005, 16, 683-696.

49. Lattova, E.; Perreault, H. N.; Krokhin, O. Matrix-Assisted Laser Desorption/Ionization Tandem Mass Spectrometry and Post-Source Decay Fragmentation Study of Phenylhydrazones of N-Linked Oligosaccharides from Ovalbumin. J. Am. Soc. Mass Spectrom. 2004, 15, 725-735.

50. Vonhelden, G. M.; Hsu, T.; Kemper, P. R.; Bowers, M. T. Structures of Carbon Cluster Ions from 3 to 60 Atoms-Linears to Rings to Fullerenes. J. Chem. Phys. 1991, 95, 3835-3837.

51. Hunter, J.; Fye, J.; Jarrold, M. F. Carbon rings. J. Phys. Chem. 1993, 97, 3460-3462.

52. Srebalus, C. A.; Li, J.; Marshall, W. S.; Clemmer, D. E. Gas-Phase Separations of Electrosprayed Peptide Libraries. Anal. Chem. 1999, 71, 3918-3927.

53. Isailovic, D.; Kurulugama, R. T.; Plasencia, M. D. Stokes, S. T. Kyselova, Z.; Goldman, R.; Mechref, Y.; Novotny, M. V.; Clemmer, D. E. Profiling of Human Serum Glycans Associated with Liver Cancer and Cirrhosis by IMS-MS. J. Proteome Res. 2008, 7, 1109-1117. 